\title{
Treatment for the Lumbosacral Soft Tissue Defect after Spine Surgery
}

\author{
Sun Jin Choi ${ }^{1}$, Chang Bum Lee ${ }^{1}$, Hyung Taek Park', \\ Jong Hoon Park', Hyeong Seok Lee ${ }^{1}$, Yong Jin Kim² \\ 'Department of Orthopaedic Surgery, Maryknoll Hospital, Busan, Korea, \\ 2Department of Orthopaedic Surgery, West Busan Centum Hospital, Busan, Korea
}

The lumbosacral area is one of the most frequently operated spine regions because of the prevalence of disease in that area. Although a lumbosacral soft tissue defect after surgery due to inflammation and other causes is rare, such soft tissue defects are difficult to treat. Therefore, suitable methods for treating lumbosacral soft tissue defects are necessary. Therefore, this study introduces a case-treated with a transverse lumbosacral rotational flap.

Key Words: Lumbar spine, Lumbosacral flap, Soft tissue defect

\section{Introduction}

Although lumbosacral soft tissue defects after back surgery are rare, this complication can be disastrous and difficult to treat. A few treatment methods have been introduced, but they are technically difficult to perform. We report a case treated with a transverse lumbosacral rotational flap, which is a simple and useful method for treating soft tissue defects after back surgery.

\section{Case Report}

A 55-year-old female visited our hospital complaining of gait disturbance and weakness on her right leg for 3 years. She had a history of back surgery at L4-5 herniated nucleus pulposus (HNP) and radiation therapy for uterine cervical cancer after a total hysterectomy. Pain and light touch senses were decreased on the right L3 to L4 dermatomes and deep tendon reflexes were not evoked in the legs. Contrac- tion of the right tibialis anterior and peroneus longus was not detected. A stoppage circumduction gait was noted during walking. The skin and soft tissue of the lower abdomen and back were stiff, hard and non-elastic because of radiotherapy. A dynamic radiographic study showed retrospondylolisthesis, L4 on L5 (Fig. 1). Magnetic resonance imaging revealed HNP with caudal migration, L4-L5, and a right posterolateral type. In addition, there was soft tissue adhesion around the nerve root. Posterior decompression and lumbar interbody fusion with cages were performed using the posterior approach (Fig. 2). It was difficult to close the skin, muscle and fascia directly because of the soft tissue defects, which were characterized by stiffness and hardness of the tissue. Therefore, the wound was left open using an interrupted wiring suture. The postoperative wound did not heal well and a serious discharge was drained consecutively. Debridement and a temporary suture were performed twice after surgery to control the surgical wound. However, healing of the soft tissue had not improved due to the sclerotic changes to the tissue and the impairment of circulation (Fig. 3). As a result, wide

Received Jun 18, 2009; 1st Revised Jul 29, 2009; 2nd Revised Aug 12, 2009; Accepted Aug 17, 2009

Corresponding author: Chang Bum Lee, MD

Department of Orthopaedic Surgery, Maryknoll Hospital,

12 Daecheong-dong 4-ga, Jung-gu, Busan 600-730, Korea

Tel: +82-51-465-8801, Fax: +82-51-463-1194, E-mail: nexgens@ hanmail.net 


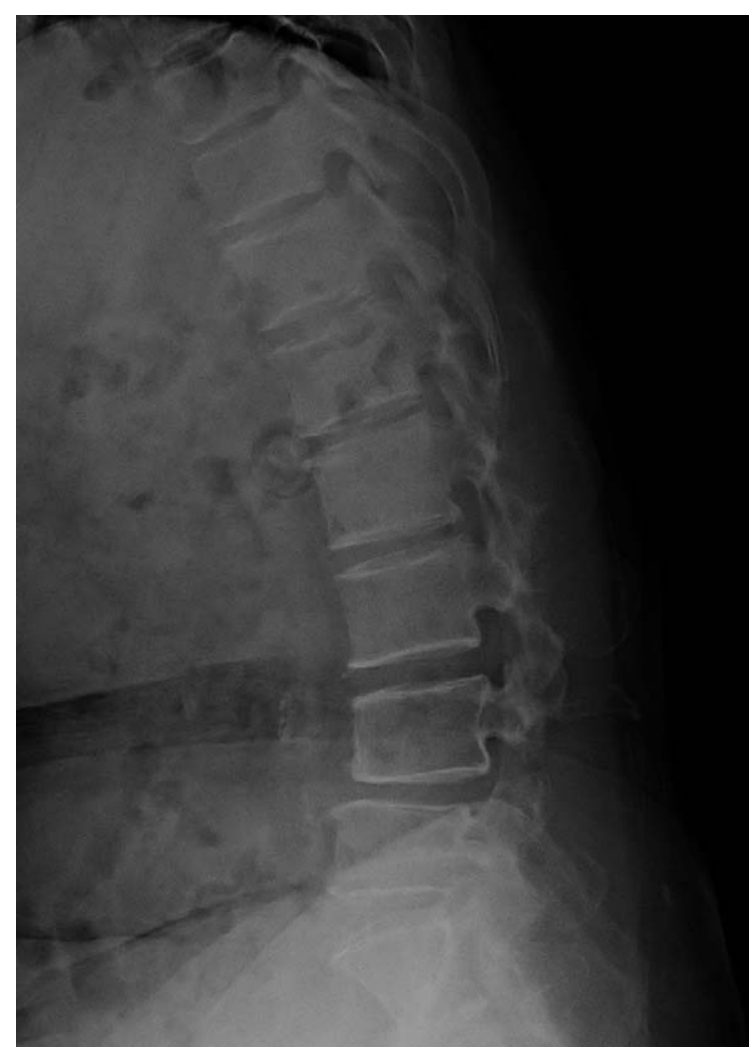

Fig. 1. Pre-operative dynamic radiographic study showing instability and retrospondylolisthesis, L4 on L5.

debridement and a transverse lumbosacral rotational flap were performed with good results and without complications (Fig. 4).

\section{Discussion}

When we encountered this case, we could not find useful methods or references despite an extensive search of the literature on plastic and microsurgery for the management of lumbosacral defects. However, most of these articles reported treatments for bed sores. In addition, they mainly used a gluteus maximus flap to treat soft tissue defects. Free or local flaps based on the perforating arteries of the gluteal resion are among the most commonly used procedures due to the excellent blood supply and adequate bulkiness [1]. On the other hand, limited shifting capacity that sacrifices the muscle in ambulatory patients is a major drawback of this procedure. In addition, they take a great deal of operating time, and there is excessive blood loss [2,3]. Occasionally, we found a suitable method by reviewing the articles. The lumbosacral flap offers a reliable and reasonable

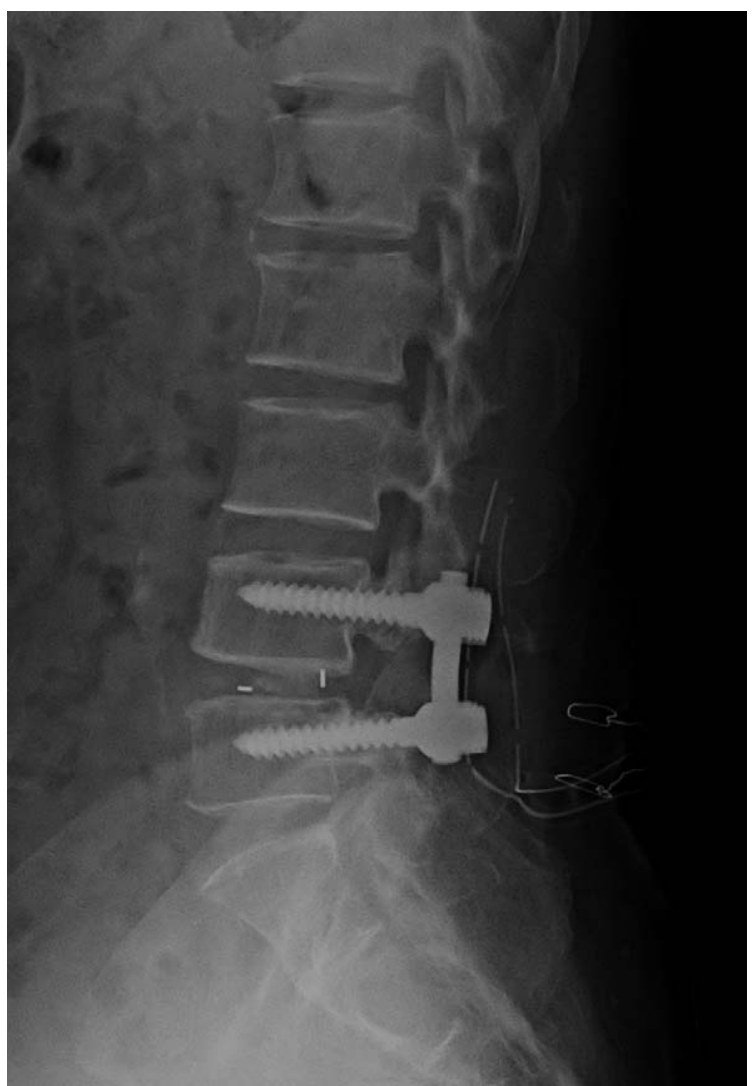

Fig. 2. Posterior decompression and lumbar interbody fusion with cages were performed using the posterior approach.

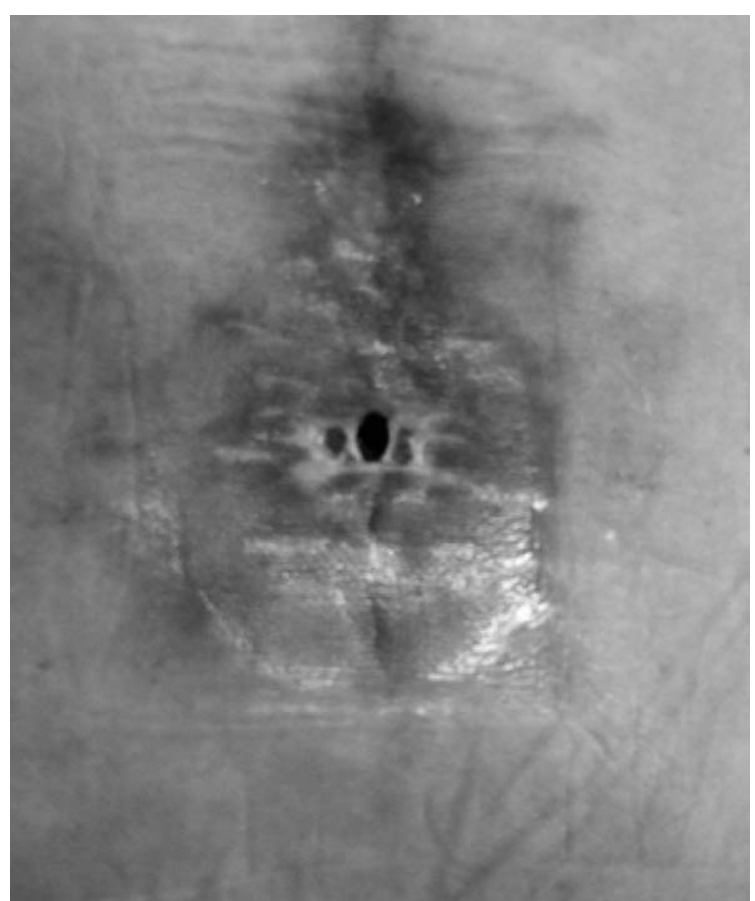

Fig. 3. The soft tissue had not healed well because of the sclerotic changes in the tissue and the impairment of circulation. 

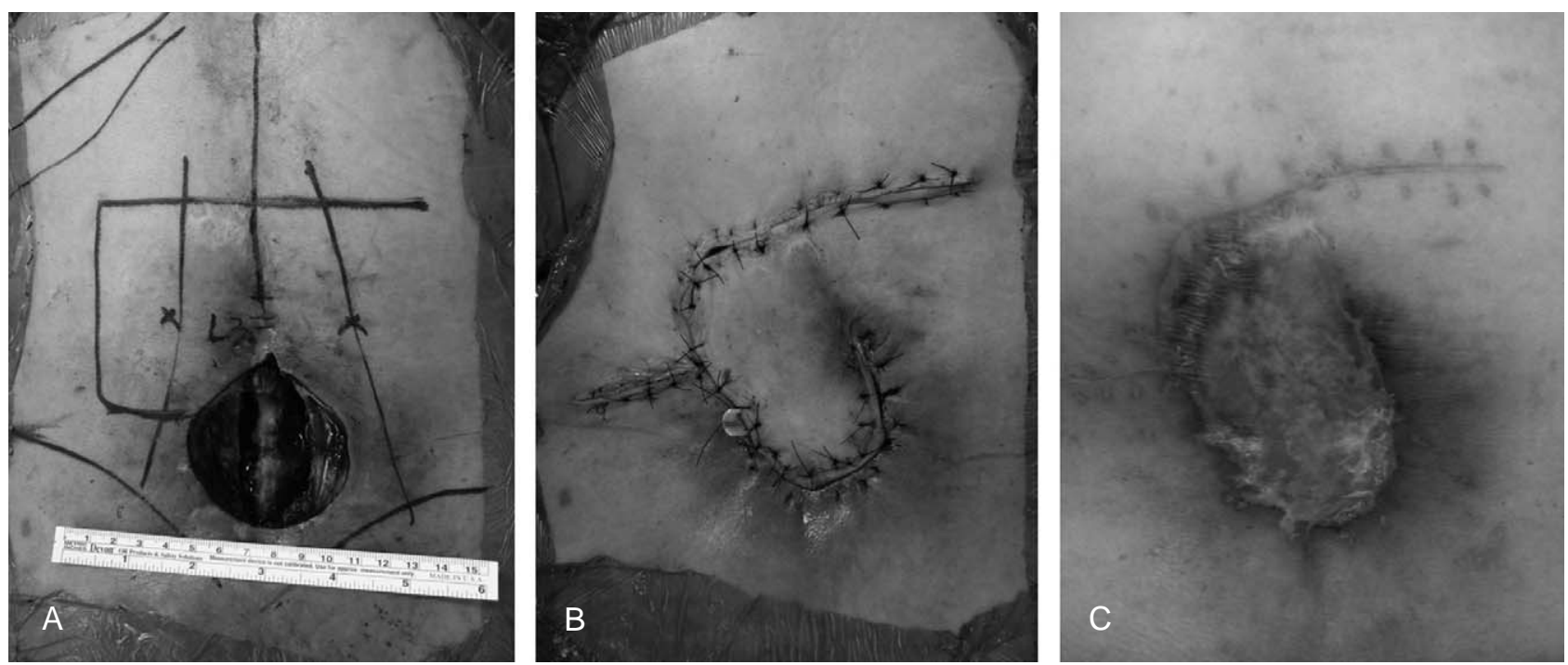

Fig. 4. Wide debridement and a transverse lumbosacral dorsal rotational flap were performed.

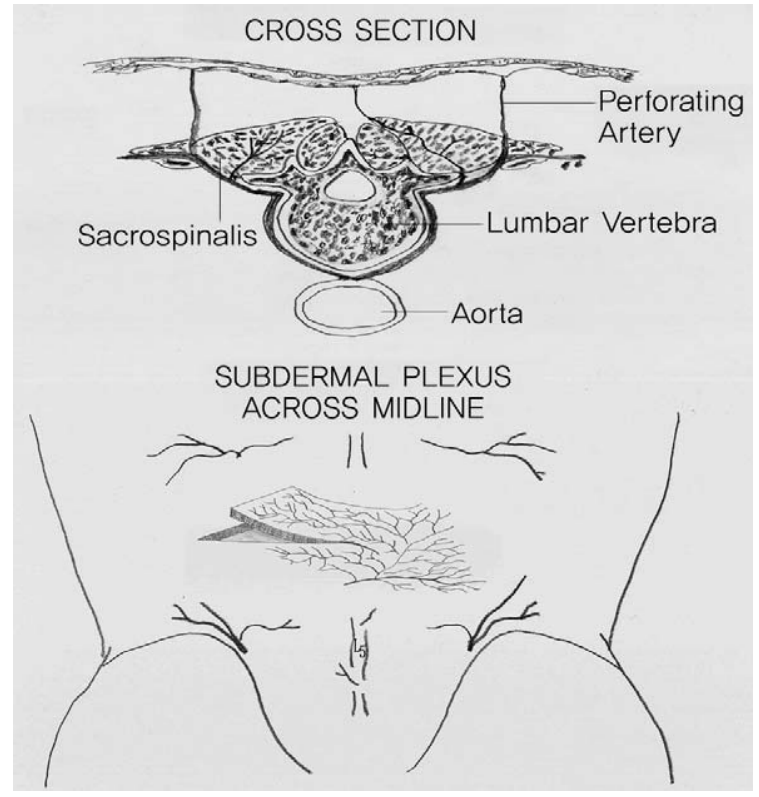

Fig. 5. Our interpretation of the subdermal plexus across the midline (regarding the contributions of the lumbar perforators).

method for the initial coverage of lumbosacral defects. Its design is anatomically sound when the lumbar perforators, which serve as the vascular pedicle, are preserved. A transverse lumbosacral flap has the following advantages: it is smaller and simple in execution; minimal loss of blood occurs; donor site defects can be closed directly; and the gluteal areas are intact for possible use later to cover recurrent or previous failed flapa [4]. The transverse lumbosacral flap is a good method for covering lumbosacral defects. Its reliability appears to be due to the axial pattern of its proximal portion, and to an uninterrupted subdermal vascular plexus (Fig. 5) across the midline of the back [5,6].

Considerable preparation is needed if a post-operative wound problem can be predicted. If there is some possibility of wound problem due to repeated surgery, immunologic diseases and radiotherapy before surgery, then operator should consider other methods, such as the anterior approach, minimal invasive surgery, and posterolateral approach. In our case, the patient had received radiotherapy 20 times for uterine cervical cancer and patient had wide previous operative scar on her abdomen as a result of a total hysterectomy. Secondarily posterior adhesiolysis was required for the nerve root entrapped by the previous operative scar tissue. Therefore, there was no choice but to perform the previous posterior approach.

A local flap is very useful for small sacral sores or skin defects. The average size of the sores for which unilateral flaps were used was $10 \times 12 \mathrm{~cm}$, while the size of the sores for which two flaps had to be raised was $22 \times 12 \mathrm{~cm}$ and 22 $\times 10 \mathrm{~cm}$ [4]. In our case, the skin defect was $7 \times 8 \mathrm{~cm}$, this unilateral flap was used easily and safely without excessive skin tension. Proper flap design is most important for achieving better results. Sufficient skin cover is essential for avoiding skin tension. The debridement of unhealthy skin and soft tissue must be performed. Overall, it is believed that a transverse lumbosacral flap is a simple and useful method for covering soft tissue defects after back surgery. 


\section{REFERENCES}

1. Kroll SS, Rosenfield L. Perforator-based flaps for low posterior midline defects. Plast Reconstr Surg 1988;81:561-6.

2. Minami RT, Mills R, Pardoe R. Gluteus maximus myocutaneous flaps for repair of pressure sores. Plast Reconstr Surg 1977;60:242-9.

3. Ramirez OM, Orlando JC, Hurwitz DJ. The sliding gluteus maximus myocutaneous flap: its relevance in ambulatory patients. Plast Reconstr Surg 1984;74:68-75.

4. Rawat SS, Mathur BS. Transverse lumbar flap for sacral bed sores. Plast Reconstr Surg 1991;88:154-8.

5. Hill HL, Brown RG, Jurkiewicz MJ. The transverse lumbosacral back flap. Plast Reconstr Surg 1978;62:177-84.

6. Smith PJ. The vascular basis of axial pattern flaps. Br J Plast Surg 1973;26:150-7. 